\title{
Using textile waste as a sustainable alternative to underground irrigation in Brazil's semi arid region
}

\begin{abstract}
The problem of water scarcity has been the subject of major discussions in society and among governments. Water is a fundamental resource for the survival of living beings and is becoming increasingly scarce, with projections showing that one in four people on Earth may be suffering from extreme water scarcity by the year 2025. Irrigation is the artificial application of water to the soil in order to maintain adequate moisture for the growth of a given crop. Among the various types of irrigation, underground irrigation is promising for use in regions with water scarcity, since water can be transported directly to the plant roots, with little loss due to surface evaporation, as happens in other types of irrigation, such as sprinkling. Thus, due to this growing water scarcity and excessive use of water by agriculture, and considering the importance of irrigation for the promotion of food and nutritional security of populations, this work presents as an alternative the use of textile waste for an application in agriculture, proposing a sustainable solution for the destination of waste from the fashion industry that is usually dumped in the trash, generating environmental problems. The development of the simple technology of subterranean irrigation based on textile residues, presented here, led to the rational use of water in constructed experimental seedbeds, without apparent damage to the development of crops, which may strengthen family farming and have a significant impact on the economic growth of the region, if the technology is applied in scale. In general, all the experimental field results demonstrated that the devices developed with pieces of synthetic textile waste were able to transport water to distant areas of the soil, keeping moist at root level and contributing to better growth of the tested plants. In other words, all the devices constructed to enable subterranean textile irrigation by capillarity worked adequately, in a qualitative analysis. The idealized and tested devices have in common the fact that they are grassroot technologies, low cost, easy to build, implement and maintain; simplicity; possibility of mastery of the technology by the beneficiaries themselves; and generators of shared knowledge between the proponents and the beneficiaries. In short, potential generators of social impact for this population that needs inclusive solutions so much.
\end{abstract}

Volume 7 Issue I - 202 I

\author{
Nicéa Ribeiro do Nascimento,' Luísa Rita \\ Brites Sanches Salvado, \\ 'Departamento de Ciência e Tecnologia Têxteis, Universidade da \\ Beira Interior, Portugal \\ ${ }^{2}$ LabCom - Comunicação e Artes, Universidade da Beira \\ Interior, Portugal
}

Correspondence: Nicéa Nascimento,

Email nicearn@hotmail.com

Received: February 15, 202। | Published: February 25, 2021

\section{Introduction}

The problem of water scarcity has been the subject of major discussions in society and among governments. Water is a fundamental resource for the survival of living beings and is becoming increasingly scarce, with projections showing that one in four people on Earth may be suffering from extreme water scarcity by the year $2025 .{ }^{1}$

In this scenario of scarcity, irrigation accounts for about $70 \%$ of groundwater and river water consumption, three times more than 50years ago. It is estimated that by 2050 , global agricultural water demand will increase by another $19 \%$. About 40 percent of the world's produced food is currently grown in artificially irrigated areas. Thus, agriculture is a major competitor for water use with people and the needs of the environment, threatening to extinguish water sources in ecosystems. ${ }^{2}$

In countries with water scarcity, the control and proper management of water use for irrigation often presents itself as a complex task. In these scenarios of good quality water deficit for irrigation, the use of non-conventional water resources (e.g. wastewater, brackish and groundwater) have been adopted in many cases as part of climate change mitigation measures to deal with the issue of water shortage. On the other hand, protected growing systems with greenhouses or screens and automatic control present themselves as sustainable options for better water use and can help reduce water scarcity in this countries. $^{1}$
Data from the United Nations show that about 844 million people around the world still do not have access to an adequate water supply for their basic needs, which is a serious public health problem, with negative consequences for the social and economic development of countries. ${ }^{3}$

Irrigation is the artificial application of water to the soil in order to maintain adequate moisture for the growth of a given crop. Among the various types of irrigation, underground irrigation is promising for use in regions with water scarcity, since water can be transported directly to the plant roots, with little loss due to surface evaporation, as happens in other types of irrigation, such as sprinkling.

Thus, due to this growing water scarcity and excessive use of water by agriculture, and considering the importance of irrigation for the promotion of food and nutritional security of populations, this work presents as an alternative the use of textile waste for an application in agriculture, proposing a sustainable solution for the destination of waste from the fashion industry that are usually dumped in the trash, generating environmental problems.

Some experiences in this sense have already been reported, such as the development of an underground water emitter composed of a ring-shaped plastic tube, with holes for water outlet and covered with a porous textile material that distributes the water better along the ring, besides reducing the chances of clogging the holes. This ring was buried around the root zone of the plant, which reduced water loss by evaporation. ${ }^{4}$ 
In another study in Indonesia, a very similar emitter was developed in the form of a rubber hose ring, also punctured at regular intervals and covered with permeable fabric. The authors reported that it is a low-cost irrigation technology that can generate benefits for small farmers who have scarce water resources. ${ }^{5}$

Therefore, subterranean capillary textile irrigation can become a good alternative for crop irrigation in dry lands and with water scarcity, such as those found in most of the Brazilian semiarid region. The textile waste from the region's apparel factories can be used for the development of simple devices that promote this type of irrigation, especially for small farms of family agriculture.

Although the technique of subsurface drip irrigation is already used in places with water scarcity, such as Africa, Israel and parts of Europe ${ }^{6}$ in Brazil it is still a little known technology, mainly because there are few low-cost devices accessible to small producers. Thus, the use of local textile waste for the development of devices that enable subterranean capillary irrigation represents a sustainable alternative to that made with sophisticated industrial equipment and devices, which contributes to the generation of income for the communities and, consequently, contributes to improve the nutritional standards of this population, ensuring food security for small producers, farmers and their families.

In this context, the present study aims to develop simple devices for subterranean textile irrigation by capillarity and evaluate their performance in typical crops of family farming in the Brazilian semiarid region.

\section{Textile waste analysis}

To characterize the textile materials to be used in the development of this work, it was necessary to identify the types of waste that could be collected from companies in the sector. Visits were made to companies in the textile sector in the city of João Pessoa, State of Paraíba, Brazil, collecting waste that was characterized.
To better meet the needs of subterranean capillary irrigation, it is desirable that the fibers of textile waste are able to transport water in the soil both horizontally and vertically, distributing evenly and effectively the little water available. Typically, fine fiber wastes with narrower capillaries lead to higher capillarity and longer liquid transport distance. For ecological reasons, biodegradable, cotton fibers that are hydrophilic and have higher wettability were also tested.

\section{Characterization of textile waste}

Seven samples of the collected textile materials were selected to perform the characterization of the physical and structural properties, with the objective of their use in textile devices for capillary subsurface irrigation. Table 1 presents the respective characterization of the selected samples. The characterizations were performed under controlled environmental conditions, at a temperature of $25^{\circ} \mathrm{C} \pm 2^{\circ} \mathrm{C}$ and relative humidity of $65 \% \pm 2 \%$, in the laboratories of the Textile Science and Technology Department of the University of Beira Interior, Portugal. In all, 5 specimens of each of the samples were tested.

The laboratory tests performed were the characterization of the textile waste samples and capillarity tests, through the COBB Test, Water Drop Test and Klemm Test (vertical capillarity). Table 2 presents the results of the first step, the characterization of the textile waste.

\section{Results of the characterization of the physical and structural properties of the textile material}

Table 2 presents the characterization results of the textile waste samples. It can be seen that there is variation in mass per unit area from $155.2 \mathrm{~g} / \mathrm{m}^{2}$ (sample 1) to $327.5 \mathrm{~g} / \mathrm{m}^{2}$ (sample 6), representing a difference of $111.02 \%$. The average thickness varied $94.92 \%$ between the highest and lowest thickness values, $315.2 \mu \mathrm{m}$ (sample 2) and $614.4 \mu \mathrm{m}$ (sample 6) respectively. Finally, the porosity of the materials varied by $45.10 \%$, between the lowest and highest value samples, samples 5 and 7 respectively.

Table I Description of the characterized materials

\begin{tabular}{|c|c|c|c|c|}
\hline Sample & Description & Tipology & Composition & Supplier \\
\hline I & Navy Stripe & Fabric & Microfiber $100 \%$ polyester & Vila Romana \\
\hline 2 & Black Stripe & Fabric & Microfiber $100 \%$ polyester & Vila Romana \\
\hline 3 & Black Stripe & Fabric & Microfiber $100 \%$ polyester & Vila Romana \\
\hline 4 & Pearl & Circular mesh & $100 \%$ naturally colored cotton & Natural Cotton Color \\
\hline 5 & Rubi & Circular mesh & Naturally Colored Cotton and White Cotton & Natural Cotton Color \\
\hline 6 & Black Lycra $^{\mathrm{TM}}$ & Circular mesh & $90 \%$ Polyamide $10 \%$ Elastane & Companhia do Corpo \\
\hline 7 & Black Lycra $^{\mathrm{TM}}$ & Circular mesh & 76\% Polyamide $24 \%$ Elastane & Companhia do Corpo \\
\hline
\end{tabular}

Table 2 Results of the characterization tests of the tissue samples [ $n=5]$

\begin{tabular}{|c|c|c|c|c|c|}
\hline Sample & Composition & Mass per unit area $\left(\mathrm{g} / \mathrm{m}^{2}\right)$ & Thickness $(\mu \mathrm{m})$ & Density $\left(\mathrm{kg} / \mathrm{m}^{3}\right)$ & Porosity \\
\hline \multirow{5}{*}{ I } & \multirow{5}{*}{$\begin{array}{l}\text { Microfiber } 100 \% \\
\text { polyester }\end{array}$} & \multirow{5}{*}{$\bar{m}=155.2 \pm 0.080$} & \multirow{4}{*}{$\bar{h}=318.2 \pm 1.6$} & \multirow{5}{*}{487.7} & \multirow{5}{*}{0.65} \\
\hline & & & & & \\
\hline & & & & & \\
\hline & & & & & \\
\hline & & & $h 5=319$ & & \\
\hline
\end{tabular}


Table continued...

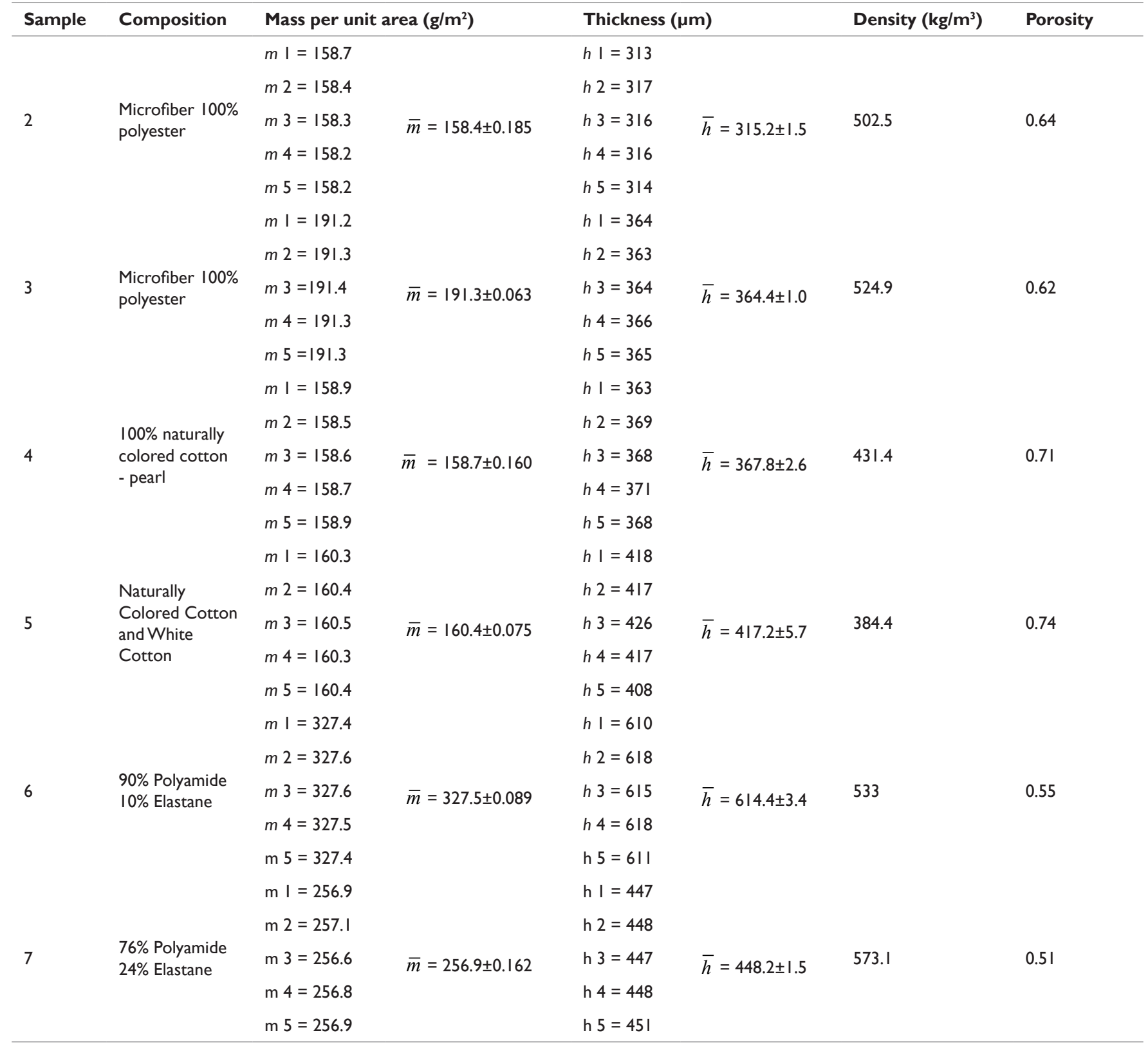

\section{Laboratory characterization of the capillarity of the textile material}

All laboratory capillarity tests were also performed under controlled environmental conditions, at a temperature of $25^{\circ} \mathrm{C} \pm 2^{\circ} \mathrm{C}$ and relative humidity of $65 \% \pm 2 \%$.

\section{Cobb test}

The Cobb Test is a standard test in the paper industry to determine the amount of liquid absorbed by paper, paperboard and corrugated paperboard ${ }^{7}$ in a given period and standardized conditions. ${ }^{8}$ Like paper, textiles are also a fibrous material, so the Cobb Test (Figure 1) can easily be applied to the characterization of woven and knitted fabrics.

For a better analysis of the results, the values of water absorbed by the sample are expressed following the equation $1^{9}$ :

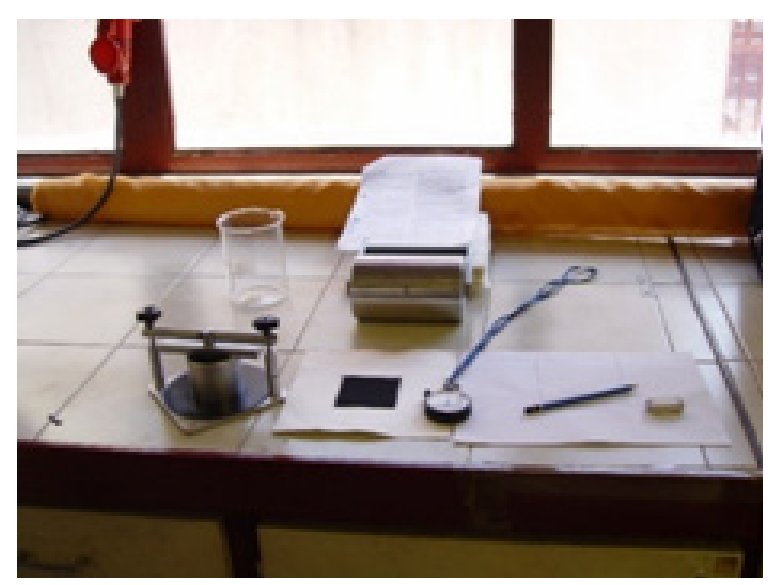

Figure I Apparatus used for measuring liquid absorption for the Cobb Test. 


$$
\Delta c o b b=\frac{m_{m}}{m_{s}} \times 100
$$

In which $m_{m}$ and $m_{s}$ are the wet and dry masses of the tested samples, respectively.

Table 3 presents the results obtained in the Cobb test.

Table 3 Results of the Cobb test

\begin{tabular}{llll}
\hline \multirow{2}{*}{ Sample } & \multicolumn{2}{l}{ Mass $(\mathrm{g})$} & \\
\cline { 2 - 3 } & $\mathbf{m s}$ & $\mathbf{m m}$ & \\
\hline 1 & 163.2 & 259.1 & 58.76 \\
2 & 167.3 & 246.9 & 47.58 \\
3 & 191.8 & 306.1 & 59.59 \\
4 & 163.2 & 193.9 & 18.81 \\
5 & 165.3 & 173.4 & 4.9 \\
6 & 351 & 467.3 & 33.13 \\
7 & 261.2 & 420.4 & 60.95 \\
\hline
\end{tabular}

Although sample 5 is composed of hydrophilic fibers (cotton), it was the one that absorbed the least water $(4.90 \%)$, characterized with the lowest volume mass $\left(384.4 \mathrm{~g} / \mathrm{m}^{3}\right)$ and the highest porosity (0.74). It should be noted that the cotton samples were not washed before the test and that naturally colored cotton has more impurities than normal cotton, which may lead the sample to create hydrophobic characteristics.

This behavior of naturally colored cotton was also analyzed by $\mathrm{Gu},{ }^{10}$ where he reports that it has $14.19 \%$ fat compared to conventional white cotton, which has only $1.8 \%$. This naturally colored cotton had a regain of $3.87 \%$ while the white cotton had a regain of $8.6 \%$. In Gu's work, ${ }^{10}$ after some washing and treatment with a $\mathrm{NaOH}$ solution, the regain of the naturally colored cotton increased to $8.69 \%$.

On the other hand, sample 7 had the best regain $(60.95 \%)$. According to Table 2, sample 7 has the lowest porosity (0.51) and the highest volumetric mass $\left(573.1 \mathrm{~kg} / \mathrm{m}^{3}\right)$. The fact that this sample is denser may mean narrower pores, which will cause greater liquid transport distances by capillarity and, therefore, higher Cobb absorption index.

In contrast, samples 1,2 and 3, which are all composed of polyester microfiber, show only a small variation in absorption indexes. The porosity and volume mass values of these samples are also similar.

\section{Water drop test}

This test consists of placing a drop of distilled water on the textile sample to be analyzed, waiting for the drop to be completely absorbed by the material, and timing it. Five specimens of each of the seven samples were tested, with dimensions of $10 \mathrm{cmx} 4 \mathrm{~cm}$. A rack was used to mechanically stabilize the sample. In this investigation, the water drop test was performed adopting the NP EN ISO 105-E07 (AATCC 104:2004) standard for Water Drop Solidity. Table 4 presents the results obtained.

Based on the results presented in Table 4, it was found that samples 4 and 5 did not show any wetting after 20 minutes. Sample 7 absorbed the water drop the fastest, and was also the least porous sample. Next come samples 1 and 3, composed of polyester microfibers.

\section{Klemm test (vertical capillarity)}

The Klemm test characterizes the vertical capillarity of textile materials through rising damp, following the ISO 8787:1986 standard. This standard evaluates water absorption by capillarity in paper and paperboard of high absorption capacities. In this case, the samples were measured several times between 2 and 45 minutes. Four specimens of each sample, with dimensions of $25 \times 2 \mathrm{~cm}$, were tested.

The best results were those of sample 3 and sample 7, presented in Table 5 and Table 6 and in the graphs shown in Figure 2 and Figure 3.

Table 7 shows the data concerning the rising damp performance of each of the samples analyzed.

As a result of this vertical capillarity test, it can be concluded that sample 3, whose composition is $100 \%$ polyester microfiber, reached an average height of $12.0 \mathrm{~cm}$, showing a satisfactory result regarding capillary rise. On the other hand, sample 7 , whose composition is $76 \%$ polyamide and $24 \%$ elastane, showed the highest average height, $15.50 \mathrm{~cm}$

Table 4 Result of the water drop test $[n=5]$

\begin{tabular}{lllllll}
\hline \multirow{2}{*}{ Sample } & \multicolumn{2}{l}{ Absorption time (minutes) } & & & \\
\cline { 2 - 7 } & Test piece I & Test piece 2 & Test piece 3 & Test piece 4 & Test piece 5 & Average [n=5] \\
\hline 1 & 0.2 & 0.13 & 0.27 & 0.67 & 0.83 & 0.42 \\
2 & 9 & 7 & 5 & 7 & 9 & 7 \\
3 & 0.42 & 0.33 & 0.33 & 0.33 & 0.33 & 0.35 \\
4 & $20^{*}$ & $20^{*}$ & $20^{*}$ & $20^{*}$ & $20^{*}$ & $20^{*}$ \\
5 & $20^{*}$ & $20^{*}$ & $20^{*}$ & $20^{*}$ & $20^{*}$ & $20^{*}$ \\
6 & 4 & 5 & 4 & 4 & 4 & 4.2 \\
7 & 0.1 & 0.1 & 0.1 & 0.1 & 0.1 & 0.1 \\
\hline
\end{tabular}

(a) After 20 minutes, it did not manifest any wetting. 
Table 5 Results of the vertical capillarity test of sample $3[n=4]$

\begin{tabular}{llllll}
\hline & Time $(\mathbf{m i n})$ & Height $(\mathbf{c m})$ & & & \\
\cline { 2 - 6 } & & Test piece I & Test piece 2 & Test piece 3 & Test piece 4 \\
\hline 2 & 2 & 3 & 3 & 3 \\
Sample 3 & 5 & 4 & 5 & 5 & 5 \\
& 10 & 7 & 8 & 9 & 9 \\
& 15 & 10 & 10 & 11 & 11 \\
& 20 & 12 & 12 & 12 & 12 \\
& 30 & 12 & 12 & 12 & 12 \\
\hline
\end{tabular}

Table 6 Results of the vertical capillarity test of sample $7[n=4]$

\begin{tabular}{llllll}
\hline & \multicolumn{5}{c}{ Height $(\mathbf{c m})$} \\
\cline { 2 - 6 } & Time (min) & Provete I & Provete 2 & Provete 3 & Provete 4 \\
\cline { 2 - 6 } & 2 & 5 & 1 & 1 & 1 \\
Sample 7 & 5 & 6 & 3 & 7 & 6 \\
& 10 & 10 & 11 & 13 & 9 \\
& 15 & 12 & 13 & 19 & 13 \\
& 30 & 13 & 15 & 19 & 15 \\
& 45 & 13 & 15 & 19 & 15 \\
\hline
\end{tabular}

Table 7 Summary of heights obtained in the vertical capillarity tests $[n=4]$

\begin{tabular}{|c|c|c|c|c|c|}
\hline Sample & Composition & $\begin{array}{l}\text { Average height at } 45 \text { minutes } \\
(\mathrm{cm})[\mathrm{n}=4]\end{array}$ & Porosity & $\begin{array}{l}\text { Tickness } \\
(\mu \mathrm{m})\end{array}$ & $\begin{array}{l}\text { Mass per area } \\
\text { unit }\left(\mathrm{g} / \mathrm{m}^{2}\right)\end{array}$ \\
\hline I & Microfiber $100 \%$ polyester & $\mathrm{II} .75$ & 0.65 & 318.2 & 155.2 \\
\hline 2 & Microfiber $100 \%$ polyester & 9.25 & 0.64 & 315.2 & 158.4 \\
\hline 3 & Microfibra $100 \%$ poliéster & 12 & 0.62 & 364.4 & 191.3 \\
\hline 5 & Naturally Colored Cotton and White Cotton & 1.75 & 0.74 & 417.2 & 160.4 \\
\hline 6 & $90 \%$ Polyamide $10 \%$ Elastane & 8 & 0.55 & 614.4 & 327.5 \\
\hline 7 & $76 \%$ Polyamide $24 \%$ Elastane & 15.5 & 0.51 & 448.2 & 256.9 \\
\hline
\end{tabular}

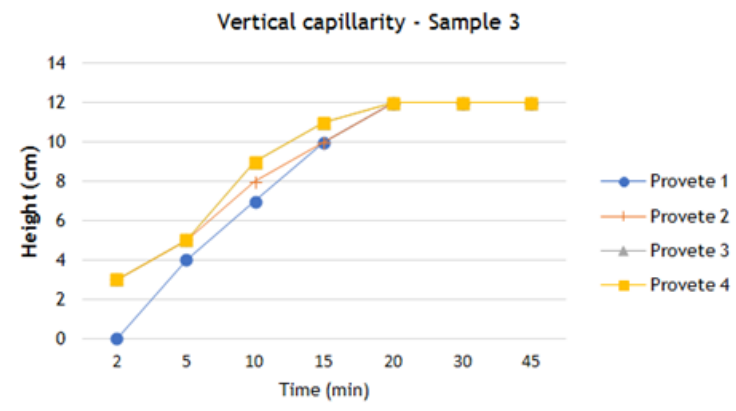

Figure 2 Graph of the vertical capillarity test results for sample $3[n=4]$.

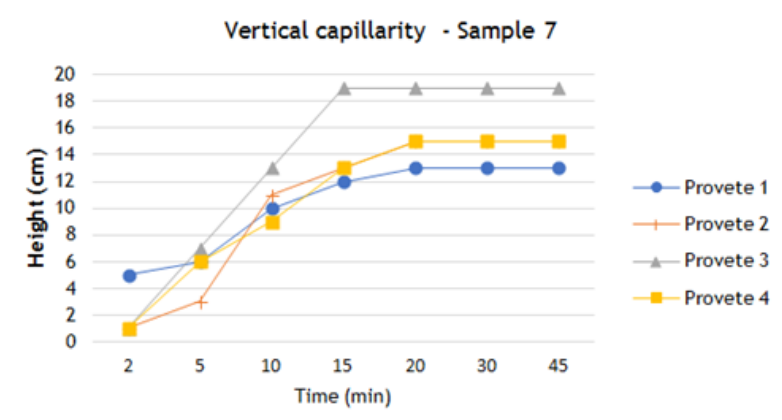

Figure 3 Graph of the vertical capillarity test results for sample 7 [n=4].

Citation: Nascimento NRD, Salvado R. Using textile waste as a sustainable alternative to underground irrigation in Brazil's semi arid region.J Textile Eng Fashion Technol. 202 I;7(I):32-44. DOI: 10.15406/jteft.202I.07.00265 


\section{Experimental laboratory for development and testing of the textile capillary devices}

For the development and tests of devices based on textile waste for the capillary subsurface irrigation of typical semi-arid crops, an experimental laboratory was built located in the municipality of São Raimundo Nonato, in the state of Piauí, Brazil, where it was possible to compare some techniques, such as micro-sprinklers, with the capillary textile subsurface irrigation.

Several control seedbeds were constructed in order to analyze in a real environment the performance of different devices and techniques of subsurface capillary irrigation. Two control seedbeds received micro-sprinkler irrigation and drip irrigation. For placement in the seedbeds, below ground level, blankets and strips of textile waste were constructed, as shown in Figure 4 and Table 8, which also shows results of horizontal capillarity tests performed at this site.

The criteria of the use of the textile waste in these devices were:

Table 8 Devices tested in the horizontal capillarity test a. As a first criterion, an attempt was made to place in the inner layer of the tapes and blankets the samples that performed well in the horizontal capillarity tests, for example, samples 6 and 7 , as active elements in moisture transport, as can be observed in devices II and IV (Table 7)

b. Next, samples from which the largest quantity was available were separated, since a lot of waste would be needed for the construction of the various devices

c. Finally, other devices were made with the remaining waste, always varying the layers, with the exception of device IV, which was built with 3 layers of sample 7 , since this was available in larger quantities and presented as one of the most promising with respect to horizontal capillarity.

Figure 5 demonstrates the layout of the experimental laboratory and Table 9 summarizes the types of seedbees, the textile waste and their respective irrigation techniques, which will be described in detail in the following sections.

\begin{tabular}{|c|c|c|c|c|c|c|}
\hline & \multirow[b]{2}{*}{ Device } & \multicolumn{3}{|c|}{ Layered constitution } & \multirow[b]{2}{*}{ Time (min) } & \multirow[b]{2}{*}{ Length of liquid transport $(\mathrm{mm})$} \\
\hline & & $\begin{array}{l}\text { Layer I } \\
\text { (external) }\end{array}$ & $\begin{array}{l}\text { Layer } 2 \\
\text { (internal) }\end{array}$ & $\begin{array}{l}\text { Layer } 3 \\
\text { (external) }\end{array}$ & & \\
\hline \multirow{3}{*}{ Blanket } & I & Sample I & Sample 2 & Sample 3 & 60 & 1200 \\
\hline & II & Sample I & Sample 6 & Sample 2 & 60 & 1500 \\
\hline & III & Sample 3 & Sample 4 & Sample 7 & 60 & 1300 \\
\hline \multirow{4}{*}{ Tapes } & IV & Sample 7 & Sample 7 & Sample 7 & 60 & 2500 \\
\hline & v & Sample I & Sample 2 & Sample 3 & 60 & 2350 \\
\hline & VI & Sample 6 & Sample 3 & Sample 6 & 60 & 2450 \\
\hline & VII & Sample 3 & Sample 5 & Sample 7 & 60 & 2000 \\
\hline
\end{tabular}

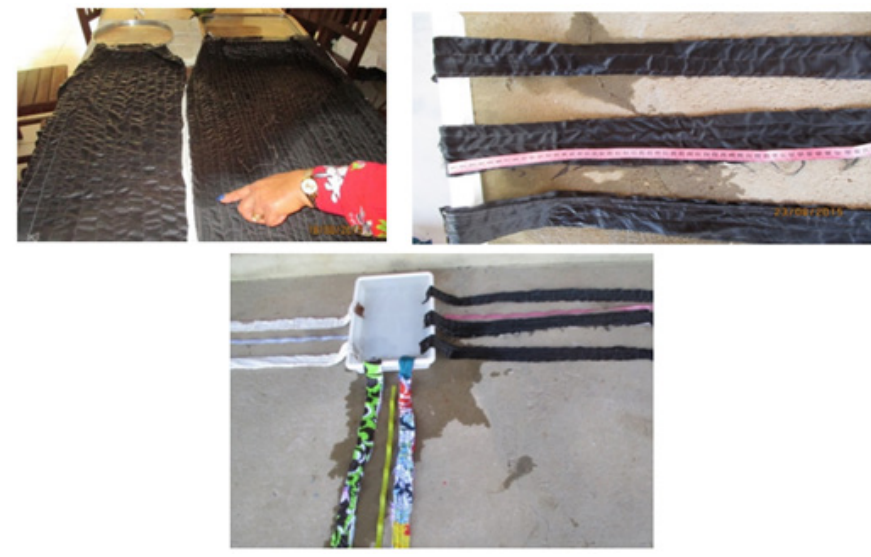

Figure 4 Built capillary devices (blankets and tapes) and horizontal capillarity tests in the field.

\section{Control Seedbeds (I and 2)}

Seedbed 1 was irrigated by micro-sprinkler using a commercial polyethylene hose. This hose has lasered perforated holes every $15 \mathrm{~cm}$, to guarantee irrigation uniformity. Seedbed 2 was irrigated by drip irrigation, also using a polyethylene hose and with drippers placed every $30 \mathrm{~cm}$.

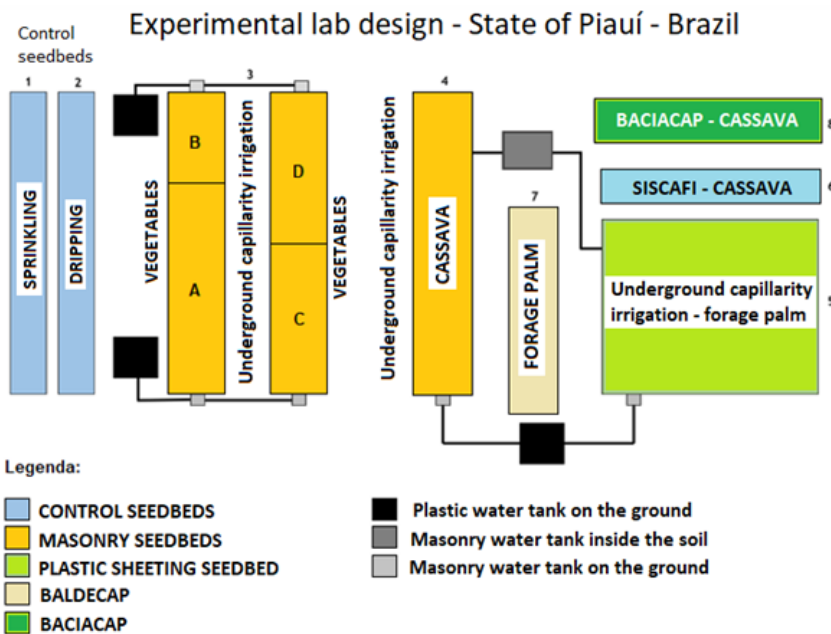

Figure 5 Graphic representation of the experimental laboratory located in Piauí State, Brazil.

In both seedbeds, the hoses were placed in the middle, according to the graphic representation in Figure 6 and the construction detail in Figure 7. 
Table 9 Overview of the experimental laboratory seedbeds in Piauí

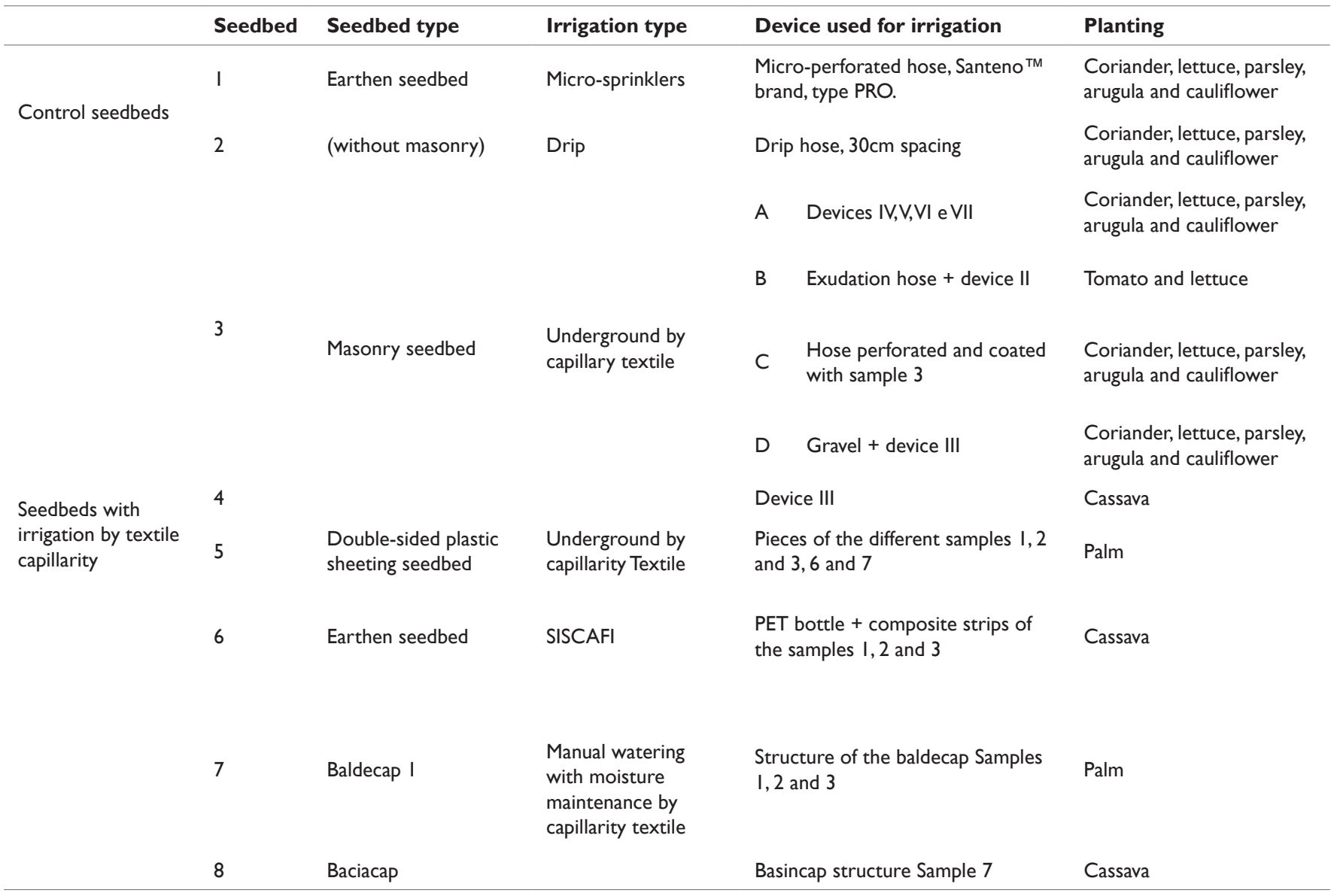

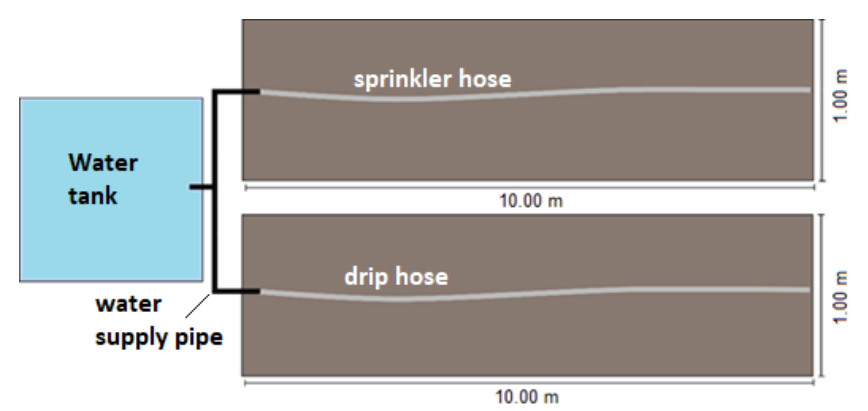

Figure 6 Graphical representation and dimensions of control seedbeds I and 2 .

\section{Seedbeds 3 (3A, 3B, 3C e 3D)}

Economic (waterproofed) masonry construction seedbeds were idealized and irrigated by the proposed new methods, underground and by capillarity, as presented below (Figure 8). Photos of the construction of this seedbed are shown in Figure 9.

\section{Seedbed 3A}

Seedbed 3A uses four PVC pipes arranged at a distance of 2 meters between each, which were supplied by a pipe connected to the water tank. On the side of each of the pipes, openings were made for the passage of textile waste wicks from one side to the other.

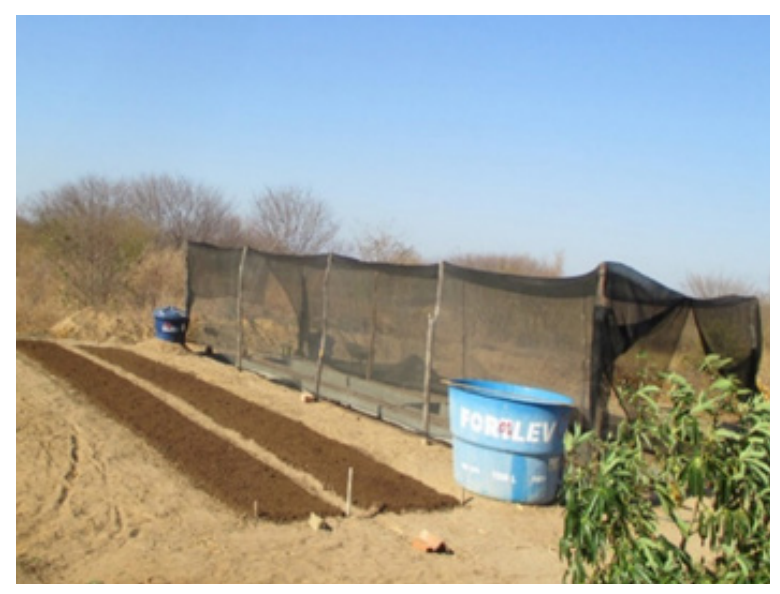

Figure 7 Control seedbeds I and 2.

\section{Seedbed 3B}

This seedbed combines industrial and artisanal irrigation techniques. The water supply pipe of this seedbed has a diameter of $25 \mathrm{~mm}$ and four outlets, $25 \mathrm{~cm}$ apart, which are connected to a $2.10 \mathrm{~m}$ long exudation hose. The exudation hose used was the Poritex hose, commercially available, and used for irrigation in semi-arid Africa, Israel and part of Europe. ${ }^{28}$ 


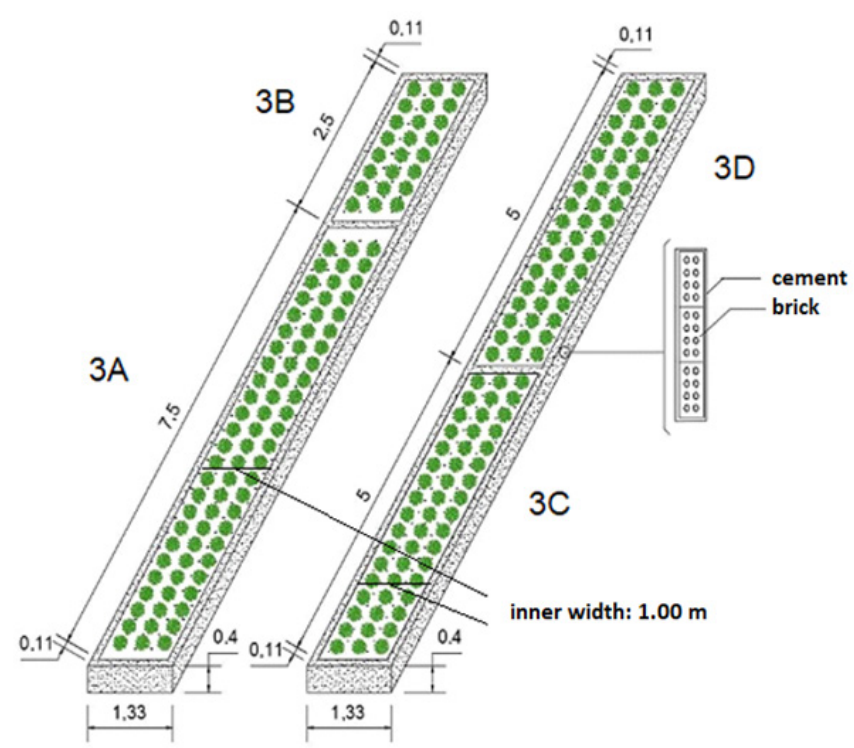

Figure 8 Graphical representation of seedbeds 3 (A, B, C and D).
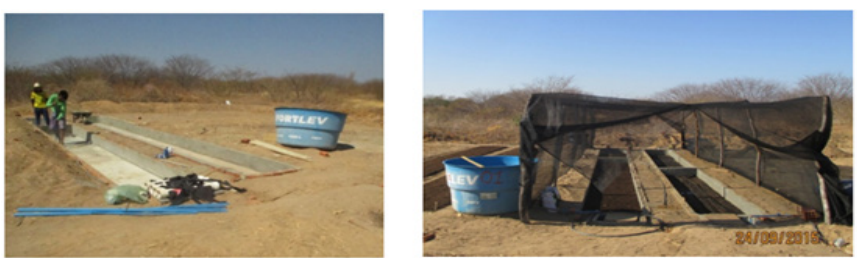

Figure 9 Construction of seedbeds $3(A, B, C$, and D) and ready for planting.

\section{Seedbed 3C}

Similar to plot 3B, plot $3 \mathrm{C}$ also combines industrial and artisanal irrigation techniques. The water supply pipe of this bed has a diameter of $25 \mathrm{~mm}$ and five outlets, with approximate distances of $20 \mathrm{~cm}$, which are connected to drip hoses with a length of $4.50 \mathrm{~m}$.

\section{Seedbed 3D}

The 3D seedbed was supplied by a $25 \mathrm{~mm}$ diameter PVC pipe, which connected a pipe from the water tank to device III (it was chosen because it was available in larger quantities), which occupied the entire area of the garden seedbed. This textile device was the only one responsible for the uniform irrigation of the seedbed.

\section{Seedbed 4}

Seedbed 4 was also built with masonry and was composed of the following layers: a $10 \mathrm{~cm}$ layer of gravel and sandy soil; then device III, totaling $33 \mathrm{~m}^{2}$ of textile waste; and finally a $10 \mathrm{~cm}$ layer of sandy soil mixed with manure.

\section{Seedbed 5}

Bed 5 was built through a hole dug in the ground and covered with a double-sided plastic tarp and with a connection to the water reservoir through a $25 \mathrm{~mm}$ pipe. In this bed, 6 layers of the respective materials were arranged: double-sided plastic tarpaulin; a $5 \mathrm{~cm}$ layer of gravel; a layer of mixture of large residues of microfiber $100 \%$ polyester fabrics (samples 1, 2 and 3); a layer of mixture of mesh residues (samples 6 and 7) randomly arranged; a $10 \mathrm{~cm}$ layer of sandy soil; and, finally, a $10 \mathrm{~cm}$ layer of sandy soil mixed with manure (Figure 10).

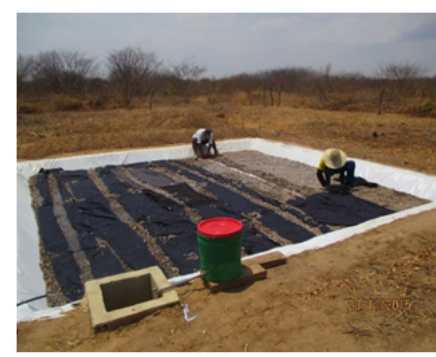

(a) (b)

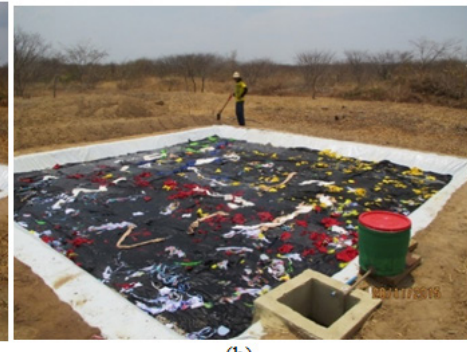

Figure 10 Construction process of building site 5 .

\section{Seedbed 6-SISCAFI}

The SISCAFI was also created, which is an irrigation system composed of reused PET bottles, buried in an upside down position, interconnected by an irrigation hose with strips of fabric placed between the inside of the bottle and the soil to be irrigated, forming wicks (Figure 11).

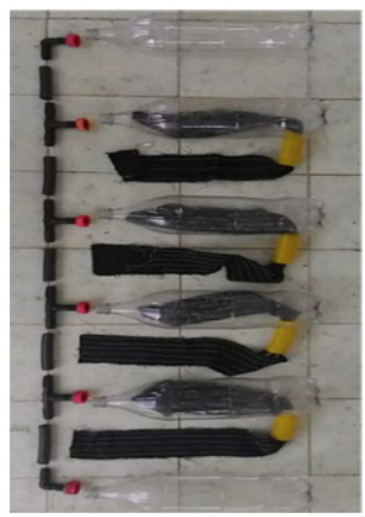

(a)

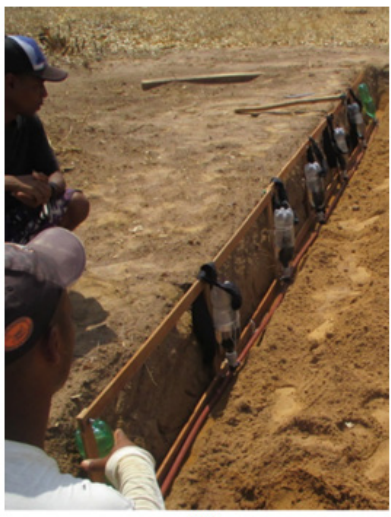

(b)
Figure I I Construction of SISCAFI

(a) ready to be installed; (b) being placed on the ground.

\section{Seedbed 7-Baldecap}

Buckets built with the ferro cement technique were buried in this bed, with the difference being that the inner surface of the bucket was coated with textile waste, making it capillary (Figure 12).
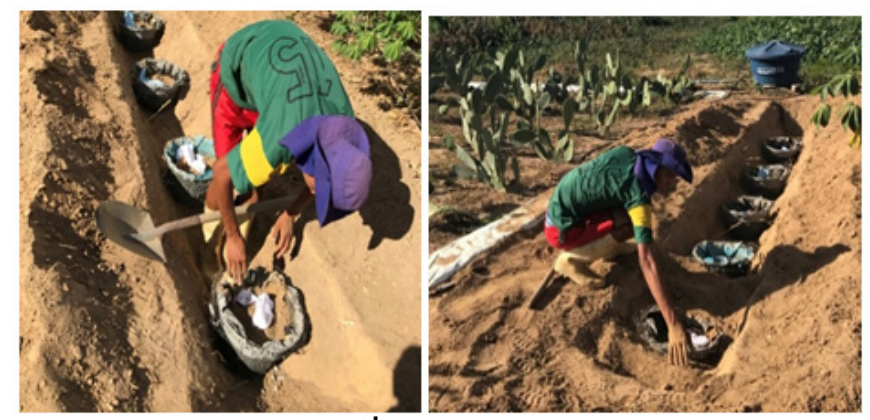

Figure 12 Construction of Seedbed 7.

\section{Seedbed 8-Baciacap}

The Baciacap is a device that uses an identical technique to the Baldecap, where the textile wastes were placed to allow the moisture in the soil placed inside them to be maintained by capillarity (Figure 13). 

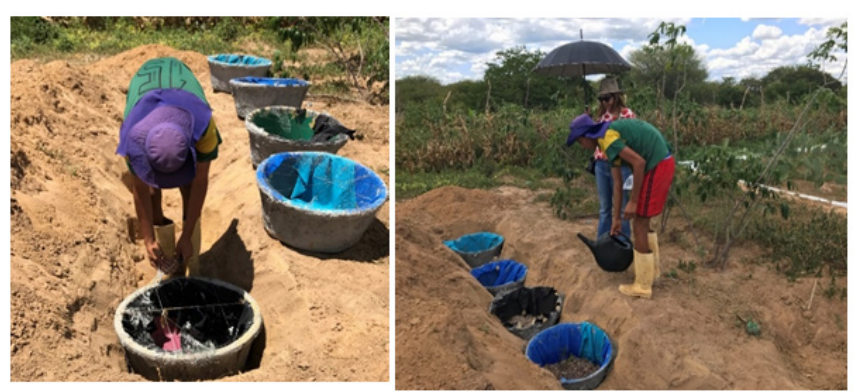

Figure 13 Construction site 8, with Baciacap.

\section{Results obtained in the laboratory}

\section{Water consumption}

To compare water consumption between seedbeds 1,2 and 3, daily measurements of consumption were taken between September 15 and 30, 2015. Considering the semi-arid climate of the region where the

Table 10 Water consumption of seedbeds I, 2 and 3 during 15 days experimental seedbeds were built, the usual temperature in September varies between a minimum of $20^{\circ} \mathrm{C}$ (night) and a maximum of $35^{\circ} \mathrm{C}$ (day).

The water consumption of seedbeds 1 and 2 was controlled by a hydrometer, while the consumption of seedbeds 3 (A, B, C and D) was calculated in relation to the height of the water inside the supply tank. The values presented in Table 9 refer to the daily consumption of each flowerbed, calculated based on initial and final values that were recorded at 5:30 am and $5 \mathrm{pm}$, respectively.

It should be noted that all the seedbeds had an initial surface irrigation before starting to record water consumption. Table 10 presents the comparative results for the water consumption of beds 1 , 2 and 3 during the 15-day period.

Looking at Table 10, it is noticeable that the control seedbeds (1 and 2) consumed far more water than the others, an average of 14.8 $1 / \mathrm{m}^{2}$, for the 15 -day period. This higher consumption was due to two main factors: evaporation, due to the high temperatures during the day; and the fact that they were not waterproofed, which caused the water to infiltrate the soil, causing losses and the impossibility of using this water by the plant roots.

\begin{tabular}{|c|c|c|c|c|c|c|c|c|}
\hline \multirow{3}{*}{ Days } & \multicolumn{8}{|c|}{ Consumption (liters) } \\
\hline & \multirow{2}{*}{$\begin{array}{l}\text { Seedbed I } \\
\text { (CI) }\end{array}$} & \multirow{2}{*}{$\begin{array}{l}\text { Seedbed } 2 \\
\text { (C2) }\end{array}$} & \multirow{2}{*}{$\begin{array}{l}\text { Average } \\
\text { (Cl e C2) }\end{array}$} & \multicolumn{5}{|c|}{ Seedbed 3} \\
\hline & & & & A & B & C & D & Average \\
\hline I & 12.5 & 6 & 9.3 & 0.4 & 0.11 & 0.12 & 0.11 & 0.19 \\
\hline 2 & 11 & 15 & 13 & 0.16 & 0.11 & 0.08 & 0.09 & 0.11 \\
\hline 3 & 9 & 9 & 9 & 0.1 & 0.05 & 0.1 & 0.07 & 0.08 \\
\hline 4 & 10 & 9 & 9.5 & 0.26 & 0.11 & 0.07 & 0.07 & 0.13 \\
\hline 5 & 13 & 18 & 15.5 & 0.15 & 0.06 & 0.11 & 0.09 & 0.1 \\
\hline 6 & 8.5 & 9.5 & 9 & 0.22 & 0.07 & 0.05 & 0.07 & 0.1 \\
\hline 7 & 7.5 & 7.5 & 7.5 & 0.34 & 0.07 & 0.1 & 0.1 & 0.15 \\
\hline 8 & 9.5 & 5 & 7.3 & 0.35 & 0.06 & 0.07 & 0.07 & 0.14 \\
\hline 9 & 6.5 & 5.5 & 6 & 0.33 & 0 & 0.09 & 0.08 & 0.13 \\
\hline 10 & 9 & 6.5 & 7.8 & 0.27 & 0 & 0.08 & 0.08 & 0.11 \\
\hline II & 8.5 & 9 & 8.8 & 0 & 0 & 0.07 & 0.08 & 0.04 \\
\hline 12 & 15 & 9 & 12 & 0 & 0 & 0.07 & 0.08 & 0.04 \\
\hline 13 & 9 & 5 & 7 & 0 & 0 & 0.07 & 0.05 & 0.03 \\
\hline 14 & 18 & 17 & 17.5 & 0 & 0 & 0.06 & 0.1 & 0.04 \\
\hline 15 & 9.5 & 8 & 8.8 & 0 & 0 & 0.07 & 0.06 & 0.03 \\
\hline Total volume of water in I5 days (I) & 156.5 & 139 & 147.8 & 2.58 & 0.64 & 1.21 & 1.2 & 1.41 \\
\hline Area of land planted $\left(\mathrm{m}^{2}\right)$ & 10 & 10 & - & 7.5 & 2.5 & 5 & 5 & - \\
\hline Final Consumption $\left(1 / \mathrm{m}^{2}\right)$ & 15.65 & 13.9 & 14.8 & 0.34 & 0.26 & 0.24 & 0.24 & 0.27 \\
\hline Amount of textile waste (all layers) $\left(\mathrm{m}^{2}\right)$ & - & - & - & 9 & 7.5 & 2.5 & 15 & 15 \\
\hline Ratio area of waste per area of the site & - & - & - & 1.2 & 3 & 0.5 & 3 & 3 \\
\hline
\end{tabular}


On the other hand, it is observed that seedbeds 3 (A, B, C and D) averaged only $0.27 \mathrm{l} / \mathrm{m}^{2}$, for the same 15 days.

The average water consumption of these four seedbeds (1.41liters) was equivalent to $0.95 \%$ of the average of the control seedbeds, which is very significant in an area as affected by water shortage as the Brazilian semiarid. This very low consumption was probably due to two reasons: the masonry waterproofing, and the capillary textile waste that was placed in the soil, at the level of the roots, keeping it moist by the capillarity phenomenon, enough for an adequate water absorption by the plant roots without the need for periodic watering.

Bed 3C obtained the best performance, since it had similar water consumption to the others $\left(0.24 \mathrm{1} / \mathrm{m}^{2}\right)$, even with a lower quantity of textile waste, with $2.5 \mathrm{~m}^{2}$ of waste for a bed of $5.0 \mathrm{~m}^{2}$ of area. That is, textile waste was placed in the proportion of half the area of the bed. In the other seedbeds, this ratio was much higher, reaching 3.0 in seedbeds 3B and 3D. These results confirm that a large amount of textile waste is not necessary to guarantee humidity, with the study indicating a ratio of textile waste area corresponding to half the area of the bed, as placed in the $3 \mathrm{C}$ bed.

The waterproofing of the seedbeds, which prevented the infiltration of water into the subsoil, and the maintenance of moisture at root level by the capillarity effect of the textile waste - happened in combination, which resulted in this excellent performance of seedbeds 3 (A, B, C and D) with respect to water consumption.

\section{Planting crops in the seedbeds}

Nine planting experiments were carried out, and the results were obtained between 30 and 35 days after planting the vegetables. It should be considered that the agriculture developed in this experimental field is family-based and organic. Therefore, the income obtained with the commercialization of the vegetables is destined to the sustenance of families that live in the semi-arid region of the Northeast.

In garden bed A, cilantro, cauliflower, lettuce, arugula, and parsley were planted, with satisfactory quality results. In Bed B, crops of lettuce, cilantro, and cherry tomatoes were planted, which also adapted satisfactorily to the form of cultivation. Lettuce was grown in Bed C, and parsley was planted in Bed D (Figure 14).

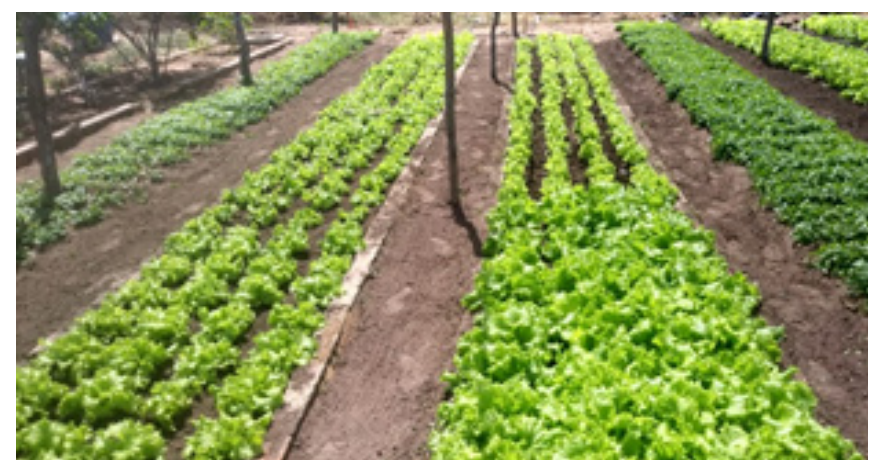

Figure 14 Overview of the planting of seedbeds 3 (A, B, C, and D).

In bed 4 (Figure 15) six seedlings of cassava were planted.

The most common cactus in the semi-arid region, the forage palm (Opuntia sp), was planted in bed 5, and it grew very vigorously, as shown in Figure 16 17).

The cassava planting was carried out in the SISCAFI bed 6 (Figure

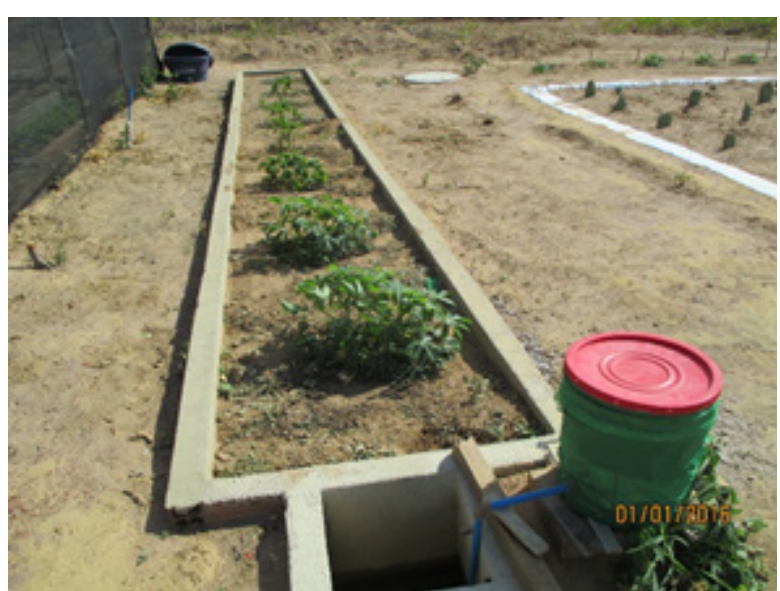

Figure I 5 Results of the cassava planting in plot 4.

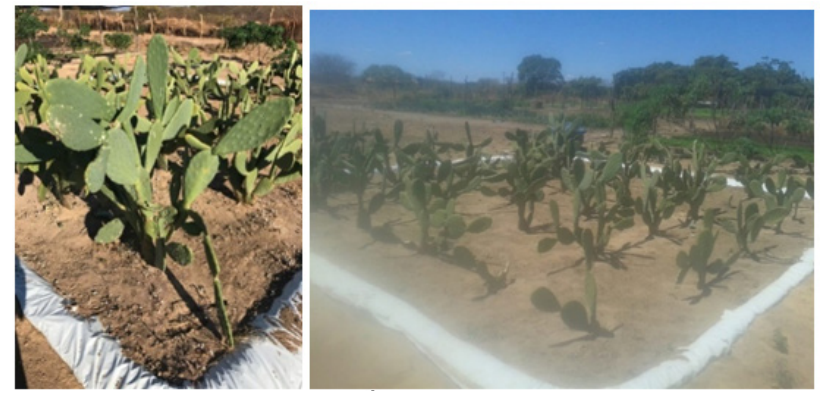

Figure 16 Result of palm planting in bed 5.

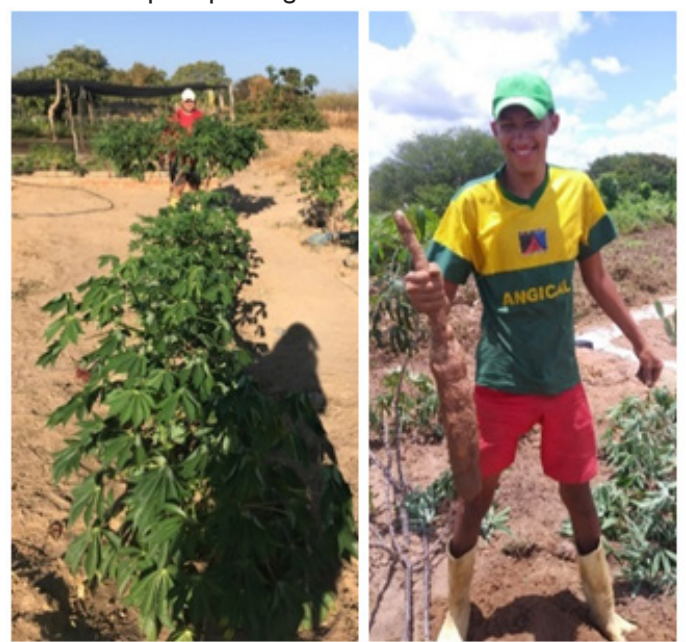

Figure 17 Result of the cassava planting in plot 6.

In seedbeds 7 and 8 (Baldecap and the Baciacap, respectively), oil palm and cassava were grown (Figure 18).

\section{Constructive aspects}

Considering the constructive aspects (ease of construction and maintenance), building site $3 \mathrm{C}$ again stands out, as it is very easy to construct. In it, the capillary devices were built with commercial plastic hoses that have micro-holes spaced at regular intervals. These hoses were coated with textile waste, which had a double function: to prevent the entry of soil into the micro-holes, avoiding clogging and, consequently, interruption of irrigation; and to provide an increase and better distribution of soil moisture, through capillarity. 


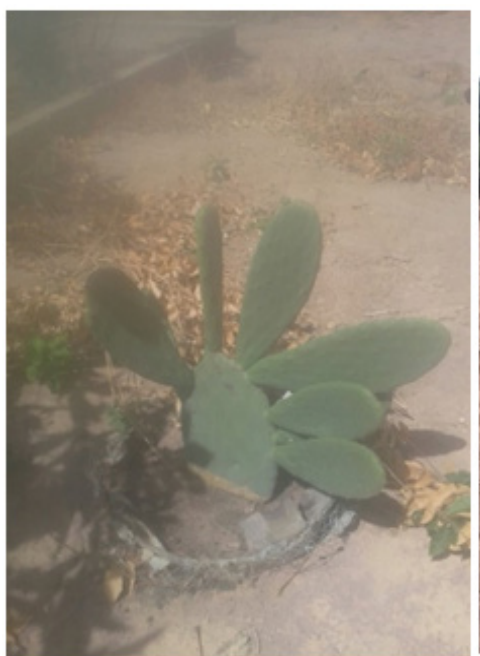

(a)

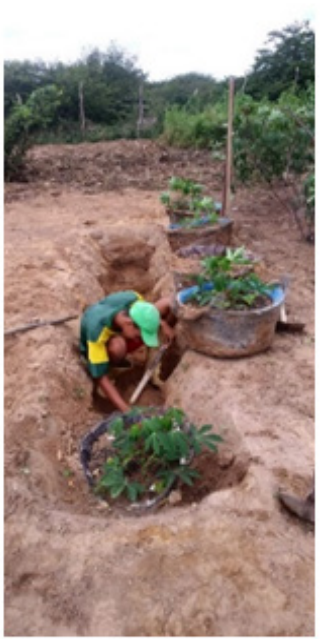

(b)
Figure I 8 Results of planting in bed 8: (a) palm; (b) cassava.

\section{Costs}

With regard to costs, as shown in Table 10, building site $3 \mathrm{C}$ has an estimated cost of $€ 1.19$ per $\mathrm{m}^{2}$, the second lowest. Building sites $3 \mathrm{~A}$ and $3 \mathrm{~B}$ were more expensive because they use special hoses and PVC pipes and fittings.

\section{Results of Seedbed 4}

This bed is similar to the 3D bed, with the difference that cassava was tested. Thus, it can be considered that this crop could be planted in the $3 \mathrm{C}$ bed, which obtained the best results (Table 11).

\section{Results of Alternative 5 to 8}

These seedbeds were built so that other alternatives to masonry seedbeds could be tested. In these seedbeds, water consumption was not monitored, obtaining significant qualitative results, such as growth and vigor of the crops. Although the devices developed and used in these seedbeds also proved the good performance of capillary textile irrigation, they proved to be a little more difficult to build, working better as alternatives for very small-scale crops, for consumption by the family itself.

\section{Proposal for a new capillary bed}

Considering globally, the constructive aspects, waterproofing and use of textile waste, the results of this study allow us to recommend, as one of its contributions, the construction of a new bed, called capillary economic bed, as shown in Figure 25, inspired by the $3 \mathrm{C}$ bed tested in the experimental laboratory.

This bed is also based on subterranean textile capillary irrigation, but with similar waterproofing as the Embrapa economic bed. ${ }^{11}$ The difference is that this new bed uses textile waste to distribute the moisture throughout the area, instead of the PVC pipe and pipe protection tiles of Embrapa's version. This solution also provides better protection for underground hoses, reducing the risk of clogging (Figure 19).

Table I I Costs of seedbeds $3 A$ to $3 \mathrm{D}$, for a standard area of $10 \mathrm{~m}^{2}$

\begin{tabular}{|c|c|c|c|c|c|c|}
\hline Item & Description & Unit & Quantity & Value per unit $(\mathbf{R} \$)$ & Total Value (R\$) & $\begin{array}{l}\text { Total Value } \\
(€)^{* *}\end{array}$ \\
\hline \multicolumn{7}{|c|}{ Seedbed 3A (corrected area for $10 \mathrm{~m}^{2}$ ) } \\
\hline I & PVC pipe, $100 \mathrm{~mm}$ diameter. & $\mathrm{m}$ & 3.2 & 6.5 & 20.8 & 3.23 \\
\hline 2 & PVC pipe. $32 \mathrm{~mm}$ diameter. & $\mathrm{m}$ & 7 & 3.8 & 26.6 & 4.14 \\
\hline 3 & PVC Fitting, "Tee", 32mm diameter. & ud. & 3 & 2 & 6 & 0.93 \\
\hline 4 & PVC Fitting, "Elbow", 32mm diameter. & ud. & 1 & 1.1 & I.I & 0.17 \\
\hline 5 & Plastic Sheeting* (200 microns) & $\mathrm{m}^{2}$ & II & 4 & 44 & 6.84 \\
\hline \multicolumn{2}{|c|}{ Total (for a $10 \mathrm{~m}^{2}$ seedbed) } & & & & & $|5.3|$ \\
\hline \multicolumn{2}{|c|}{ Cost $\left(\mathrm{I} \mathrm{m}^{2}\right)$} & & & & & 1.53 \\
\hline \multicolumn{7}{|c|}{ Seedbed 3B (corrected area for $10 \mathrm{~m} 2$ ) } \\
\hline I & Porous hose I/2" diameter. & $\mathrm{m}$ & 38 & 4 & 152 & 23.63 \\
\hline 2 & PVC Fitting, "Tee", 20mm diameter. & ud. & 3 & 1 & 3 & 0.47 \\
\hline 3 & PVC Fitting, "Elbow", 20mm diameter. & ud. & 2 & 0.5 & I & 0.16 \\
\hline 4 & PVC Pipe, $20 \mathrm{~mm}$ diameter. & $\mathrm{m}$ & 1 & 2.5 & 2.5 & 0.39 \\
\hline 5 & Plastic Sheeting* (200 microns) & $\mathrm{m}^{2}$ & II & 4 & 44 & 6.84 \\
\hline \multicolumn{2}{|c|}{ Total (for a $10 \mathrm{~m}^{2}$ seedbed) } & & & & & 31.49 \\
\hline \multicolumn{2}{|c|}{ Cost $\left(\mathrm{Im}^{2}\right)$} & & & & & 3.15 \\
\hline \multicolumn{7}{|c|}{ Seedbed $3 C$ (corrected area for $\left.10 \mathrm{~m}^{2}\right)$} \\
\hline I & Plastic hose, $16 \mathrm{~mm}$ diameter. & $\mathrm{m}$ & 50 & 0.5 & 25 & 3.89 \\
\hline 2 & PVC Fitting, "Tee ", 20mm diameter. & ud. & 4 & 1 & 4 & 0.62 \\
\hline 3 & PVC Fitting, "Elbow", 20mm diameter. & ud. & 2 & 0.5 & I & 0.16 \\
\hline
\end{tabular}


Table continued...

\begin{tabular}{|c|c|c|c|c|c|c|}
\hline Item & Description & Unit & Quantity & Value per unit $(\mathbf{R} \$)$ & Total Value (R\$) & $\begin{array}{l}\text { Total Value } \\
(€)^{* *}\end{array}$ \\
\hline 4 & PVC Pipe, $20 \mathrm{~mm}$ diameter. & $\mathrm{m}$ & 1 & 2.5 & 2.5 & 0.39 \\
\hline 5 & Plastic Sheeting* (200 microns) & $\mathrm{m}^{2}$ & 11 & 4 & 44 & 6.84 \\
\hline \multicolumn{6}{|c|}{ Total (for a $10 \mathrm{~m}^{2}$ seedbed) } & 11.9 \\
\hline \multicolumn{6}{|c|}{ Cost $\left(\mathrm{Im}^{2}\right)$} & 1.19 \\
\hline \multicolumn{7}{|c|}{ Seedbed 3D (corrected area for $10 \mathrm{~m} 2$ ) } \\
\hline I & Plastic Sheeting* (200 microns) & $\mathrm{m}^{2}$ & 11 & 4 & 44 & 6.84 \\
\hline \multicolumn{6}{|c|}{ Total (for a $10 \mathrm{~m}^{2}$ seedbed) } & 6.84 \\
\hline \multicolumn{6}{|c|}{ Cost $\left(\mathrm{Im}^{2}\right)$} & 0.68 \\
\hline
\end{tabular}

(*) Cheapest option for waterproofing; (**) Base price 08.I7.2020: I€ $=\mathrm{R} \$ 6.43$.

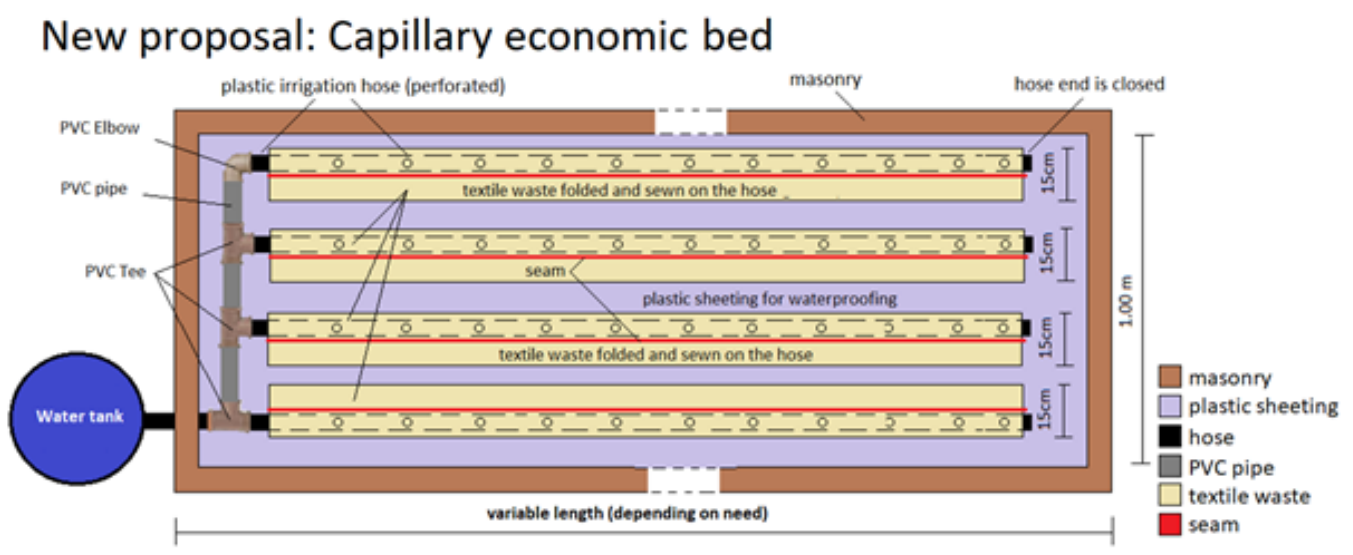

Figure 19 Capillary economic bed.

To promote textile irrigation by capillarity, one should use simple irrigation hoses or pipes, made of recycled plastic, with holes every $30 \mathrm{~cm}$, covered with approximately $30 \mathrm{~cm}$ of synthetic textile waste sewn over the hose, forming a $15 \mathrm{~cm}$ wide tape that will better distribute the moisture throughout the area of the bed and protect the holes from clogging.

It is also suggested to use synthetic textile waste similar to samples $1,2,3,6$ and 7 , i.e. $100 \%$ polyester microfiber fabric (samples 1 to 3 ) or polyamide and elastane knits (samples 6 and 7).

\section{Conclusion}

The development of the simple technology of subterranean irrigation based on textile residues, presented here, led to the rational use of water in constructed experimental seedbeds, without apparent damage to the development of crops, which may strengthen family farming and have a significant impact on the economic growth of the region, if the technology is applied in scale.

The aggregation of value to the productive process is evidenced by the use of textile residues that contribute to a greater profitability of family agriculture over time. The material used can be reused from waste from the region where it will be used. Although the textile residues are not biodegradable, they are well located in the impermeable seedbeds and can be removed if the farmer wishes to end production, not polluting the environment.

Throughout the life of the bed, the textile waste keeps the soil irrigated and makes production possible with low water consumption in the Brazilian semiarid region.
It is important to make available new simple technologies that help the growth of family profitability through the use of waste that can be considered a zero cost investment, considering that, in Brazil alone, there is production of tons of textile waste per day, i.e., this factor alone makes the experience of subterranean textile irrigation by capillarity presented in this work feasible.

The use of textile waste presented here can be a sustainable alternative for the use of textiles that would be discarded, since the large numbers of micro-enterprises that use textiles in the Brazilian semiarid region generate a large volume of textile waste. Although the handicraft industry in the semi-arid region absorbs part of this waste, most of what is produced by the textile industry is still dumped inadequately into the environment. In addition, the factories that recycle textiles are concentrated in the South and Southeast regions of Brazil, which is a problem for the Northeast region, especially the semi-arid one, due to the high costs of an eventual waste transportation operation to the South or Southeast, making this possibility unfeasible.

In general, all the experimental field results demonstrated that the devices developed with pieces of synthetic textile waste were able to transport water to distant areas of the soil, keeping it moist at root level and contributing to better growth of the tested plants. In other words, all the devices constructed to enable subterranean textile irrigation by capillarity worked adequately, in a qualitative analysis.

The idealized and tested devices have in common the fact that they are grass root technologies, low cost, easy to build, implement and maintain; simplicity; possibility of mastery of the technology by the beneficiaries themselves; and generators of shared knowledge 
between the proponents and the beneficiaries. In short, potential generators of social impact for this population that needs inclusive solutions so much.

The use of these simple technologies can bring countless benefits to the development of crops and family farming in the region, mainly because it is a small-scale irrigation device, although it is as effective as other sophisticated and expensive devices used in large agricultural projects. Moreover, because it is a simple system, whose maintenance is accessible to farmers, even those with little formal education, it is a modern technology that does not require complex training or skilled professionals to supervise and/or repair the devices.

\section{Acknowledgments}

None.

\section{Funding}

None.

\section{Conflicts of interest}

No potential conflict of interest was reported by the authors.

\section{References}

1. Nikolaou G, Neocleous D, Christou A, et al. Implementing sustainable irrigation in water-scarce regions under the impact of climate change. Agronomy. 2020;10(8):1120.
2. Globalagriculture. Water - agriculture at a crossroads - business as usual is not an option. 2020 .

3. Unwater. SDG 6 synthesis report 2018 on water and sanitation. 2008.

4. Sumarsono J, Setiawan BI, Subrata IDM, et al. Ring-typed emitter subsurface irrigation performances in dryland farmings. International Journal of Civil Engineering and Technology. 2018;9(1):797-806.

5. Saefuddin R, Saito H, Šimůnek J. Experimental and numerical evaluation of a ring-shaped emitter for subsurface irrigation. Agricultural Water Management. 2019;211:111-122.

6. Megersa G, Abdulahi J. Irrigation system in Israel: A review. International Journal of Water Resources and Environmental Engineering. 2015;7(3):29-37.

7. TAPPI 441 om-90. Water absoptiveness of sized (non-bibulous) paper and paperboard (Cobb test). Technical association of the Pulp and Paper Industry; 1960.

8. ISO 535:1976. Paper and board - Determination of water absorption Cobb method.

9. Morton WE, Hearle JWS. Physical properties of textile fibers. 4th edn. Cambridge: Woodhead Publishing Limited; 2008.

10. Gu H. Research on the improvement of the moisture absorbency of naturally self-coloured cotton. $J$ Text Inst. 2005;96(4):247-250.

11. ACBCrato. Learn how to make an economical construction site. 2021. 